\title{
Substituindo a fé em Deus pela fé na Ciência: A cobertura do Diário Catarinense sobre o relatório do IPCC
}

\author{
Replacing faith in God by faith in Science: \\ Diário Catarinense's coverage of the IPCC report
}

\section{Sustitución de la fe en Dios por la fe en la ciencia: La cobertura del Diário Catarinense de lo informe del IPCC}

\author{
Jorge Kanehide Ijuim ${ }^{l}$ \\ Cristian Madalena Derosa ${ }^{2}$
}

\section{Resumo}

Este trabalho se propõe a analisar o tema "Mudanças Climáticas e Aquecimento Global" no jornal Diário Catarinense (DC), no período em que foi publicado o quarto relatório do Painel Intergovernamental de Mudanças Climáticas (IPCC), em 2007. O objetivo é verificar o modo como se deu a adesão do jornal à opinião de uma parte da comunidade científica, representada pelo relatório, em detrimento de outras visões sobre o fenômeno climático. Buscando delinear as influências da agenda midiática (McCombs, 2009), examinamos uma amostra de matérias do DC, por meio da análise de conteúdo (Hercovitz, 2008), de modo a compreender de que forma essa adesão foi discursivamente construída. O segundo objetivo deste estudo é procurar entender os porquês de a Imprensa - em particular o Diário Catarinense - concentrar seu noticiário nas fontes oficiais. Para tanto, trazemos à discussão uma crítica à Ciência Moderna desenvolvida por Boaventura de Sousa Santos (2010).

\begin{tabular}{|c|c|}
\hline \multirow{3}{*}{ 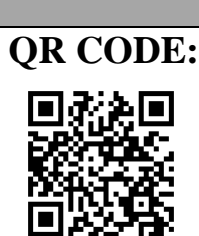 } & Acesse este artigo online \\
\hline & $\begin{array}{l}\text { Website: } \\
\text { http://www.revistas.ufg.br/index.php/ci }\end{array}$ \\
\hline & $\begin{array}{l}\text { DOI: } \\
\text { http://dx.doi.org/10.5216/ci.v20i1.40572 }\end{array}$ \\
\hline
\end{tabular}

Palavras-chave: Ciência e Jornalismo. Jornalismo ambiental. IPCC. Mudanças climáticas. Diário Catarinense.

\begin{abstract}
This study aims to analyze coverage of Climate Change and Global Warming in the newspaper Diário Catarinense (DC) during the period in which the fourth IPCC - Intergovernmental Panel on Climate Change (2007) report was published. Its goal is to see how the newspaper joined in the opinion of a part of the scientific community represented by the report instead of other views of the weather phenomenon. Aiming to define the influences of the media agenda (McCombs, 2009), we examined a sample of DC stories through content analysis (Hercovitz, 2008) in order to understand how this support was constructed in discourse. The second goal of this study is to try to understand the reasons for the press' - particularly the Diário Catarinense's - to produce their coverage focusing on official

1 Jornalista; doutor em Ciências da Comunicação/Jornalismo pela ECA/USP; professor de Jornalismo da Universidade Federal de Santa Catarina (UFSC). Brasil, Santa Catarina, Florianópolis. E-mail: ijuimjor@gmail.com

2 Jornalista; mestre pelo Programa de Pós-graduação em Jornalismo da Universidade Federal de Santa Catarina. Brasil, Santa Catarina, Florianópolis. E-mail: cristianderosa @ hotmail.com
\end{abstract}

Comun. \& Inf., Goiânia, GO, v. 20, n. 1, p. 115-130, jan./jun. 2017 
sources. For that end, we bring to the discussion a critique of modern science developed by Boaventura de Sousa Santos (2010).

Keywords: Science and Journalism. Environmental journalism. IPCC. Climate changes. Diário Catarinense.

\section{Resumen}

Este estudio tiene como objetivo analizar el tema del cambio climático y el calentamiento global en el periódico Diário Catarinense (DC) en el período en que se publicó el cuarto informe del IPCC - Grupo Intergubernamental de Expertos sobre el Cambio Climático (2007). El objetivo es ver cómo se dieron la adhesión del periódico a la opinión de parte de la comunidad científica representada por el informe sobre otros puntos de vista sobre el fenómeno climático. Con el objetivo de definir las influencias de la agenda de los medios (McCombs, 2009), se analizó una muestra de los materiales de DC, a través de análisis de contenido (Hercovitz, 2008), con el fin de comprender cómo esta adhesión se construyó discursivamente. El segundo objetivo de este estudio es tratar de entender las razones de la prensa - en particular el Diário Catarinense - enfocar sus noticias en las fuentes oficiales. Para eso, traemos a la discusión crítica de la ciencia moderna desarrollada por Boaventura de Sousa Santos (2010).

Palabras-clave: Ciencia y periodismo. Periodismo ambiental. IPCC. El cambio climático. Diário Catarinense.

\section{O RELATÓRIO DO IPCC COMO FENÔMENO MIDIÁTICO}

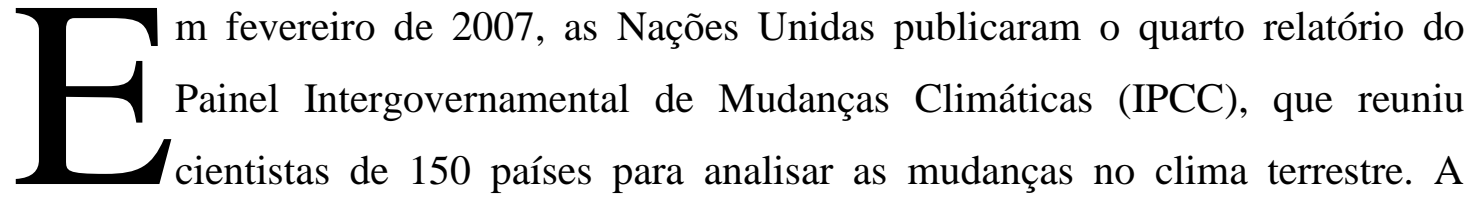
publicação do documento mobilizou a imprensa do mundo inteiro e o assunto se tornou amplamente debatido nos diferentes âmbitos da sociedade.

Como conclusões científicas, o relatório apontava o preocupante cenário de um aquecimento da atmosfera e enumerava consequências como o aumento do nível do mar, extinção de espécies, além de mudanças drásticas na geografia terrestre e, posteriormente, na economia mundial. A principal causa que concorria para isso, segundo os cientistas, era a influência do homem no meio ambiente por meio da emissão de gases de efeito estufa, fruto da crescente industrialização.

Embora a opinião científica sobre essas causas não formasse nenhum consenso no campo da ciência, as conclusões do IPCC foram interpretadas pela imprensa como algo irreversível, decisivo e, portanto, consensual entre os cientistas. Afinal, o relatório salientava que havia $90 \%$ de chances de o fenômeno ser causado pelo homem, ou seja, dos prognósticos científicos estarem corretos. Na imprensa, porém, chegou-se a dizer que esses $90 \%$ se referiam ao percentual de culpa humana no fenômeno. Muitos cientistas vieram a público 


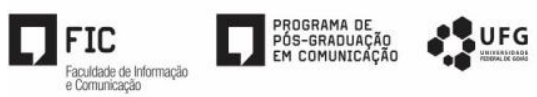

chamando a atenção para as distorções da mídia e a pouca divulgação da divergência que havia entre os próprios cientistas responsáveis pelas pesquisas do relatório.

Diante disso, pesquisadores de comunicação começaram a se interessar por esse fenômeno midiático que produzia reportagens alarmistas e que concedia pouca publicidade a ideias contrárias à tese do chamado aquecimento antropogênico, de causas humanas. A publicação do relatório do IPCC e sua divulgação deram grande impulso à causa ambiental já existente há décadas, reforçando a sua imagem como novo paradigma de desenvolvimento.

O ambientalismo se tornou rapidamente um emergente código moral, com seus prognósticos técnicos e códigos de conduta que iam além da vida social, passando por responsabilidades individuais e recomendando comportamentos sociais, políticos, empresariais e governamentais ditos ecologicamente corretos. Essa nova visão parecia basearse na interpretação de resultados de uma única comunidade científica, cuja opinião era tida como homogênea e consensual.

Esse pensamento único que a mídia privilegiava chamou a atenção de pesquisadores como Painter (2010) que notou nas páginas dos jornais a pouca presença de opiniões contrárias à hipótese antropogênica. A partir de uma análise de conteúdo nos jornais brasileiros "Folha de São Paulo" e "O Estado de São Paulo", entre fevereiro e junho de 2007, o estudo de Painter revelou que de $1 \%$ a $3 \%$ dos artigos de opinião apresentavam o posicionamento cético, bem diferente dos jornais de países como o Reino Unido (de $4 \%$ a $23 \%$ ) e EUA (de 13\% a 40\%). O trabalho de Painter abrangia jornais de 50 países.

Outra pesquisa que se concentrou na forma como o jornalismo ambiental brasileiro abordou a questão foi o relatório da ANDI - Comunicação e Direitos (2008), que detalhou a cobertura a partir do monitoramento de 50 jornais de 26 estados brasileiros e do Distrito Federal, entre julho de 2005 e dezembro de 2008. O objetivo do estudo foi avaliar em que medida questões relacionadas ao fenômeno das Mudanças Climáticas repercutem na imprensa nacional e investigar a qualidade desse conteúdo. Os resultados da análise de textos publicados entre 2005 e 2007 evidenciaram um aumento significativo no número de matérias sobre Mudanças Climáticas. Essa mesma tendência foi observada em pesquisas internacionais de acordo com o relatório.

Os resultados dessas duas pesquisas levam a um questionamento acerca da influência que o tratamento de temas científicos e ambientais pode exercer nas pautas públicas e na sua relação com agendas políticas internacionais. Um dos caminhos de reflexão dessas questões 
pode estar nas perguntas que originaram teorias como a Agenda-Setting (Agendamento), de McCombs e Shaw (2009).

A preocupação com as relações entre as agendas públicas e políticas levou ao estudo dos fatores formadores da agenda da mídia. A influência exercida entre agendas políticas ou governamentais, no conjunto de hábitos profissionais do jornalismo para tentar definir as aspirações do público, tornou-se um dos principais objetos de estudo da teoria do agendamento.

O Diário Catarinense (DC), como veremos nas próximas linhas, assumiu em suas páginas: 1) a agenda da ONU e 2) o discurso ditado pelo Quarto Relatório do IPCC.

\section{A ADESÃO DO DC AO IPCC}

O jornal Diário Catarinense foi fundado em maio de 1986, em Florianópolis, e tem abrangência estadual. De acordo com dados institucionais publicados em seu site, o jornal circula em 243 dos 293 municípios catarinenses. Sua tiragem alcança 38 mil exemplares (durante a semana) e, no domingo, esse número chega a 56 mil. Esses dados, segundo a página institucional, colocam o DC como o jornal líder do mercado de veículos impressos em Santa Catarina. O número de leitores estimado é de 217 mil. Desses, seu público principal é formado por leitores jovens: 39\% estão na faixa etária que vai dos 25 aos 39 anos; $24 \%$ pertencem à faixa de idade que vai dos 15 aos 24 anos.

De janeiro a julho de 2007, período escolhido para análise, o DC publicou 212 das quais analisamos 12.076 textos entre notícias, notas, reportagens, editoriais e artigos de opinião. Considerando esse corpus, a cobertura total sobre Mudanças Climáticas representou 0,79\%. Um percentual de $93 \%$ do total de textos é representado por notícias, reportagens e notas. Desse montante, 57 matérias, ou seja, 0,5\% do total, tratavam das Mudanças Climáticas, nos quais o relatório IPCC esteve presente como fonte primária ou secundária, mas desempenhou função de definidor primário.

A seguir, apresentaremos duas das peças jornalísticas selecionadas entre a amostra e analisadas sob alguns aspectos. Elas marcam com propriedade o tom do discurso construído pelo jornal:

\subsection{Primeira matéria em análise: "Revelação alarmante"}

A matéria, publicada em 3 de fevereiro de 2007, leva o título "Terra à beira da catástrofe", sob a cartola "Aquecimento Global". 
O alerta lançado por um comitê internacional de cientistas, ontem, na França, desdobra-se em três inquietações para a humanidade. Primeira: o aquecimento global é inequívoco. Segunda: $90 \%$ da culpa são do homem. Terceira: os efeitos persistirão nos próximos séculos, mesmo que parem as emissões dos gases causadores do efeito estufa. (grifo nosso)

O lead apresenta três constatações presentes no Relatório do IPCC, que classifica como "inquietações para a humanidade". A primeira é que o Aquecimento Global é inequívoco, colocando as conclusões dos cientistas do comitê longe da possibilidade de dúvida. A segunda, a de que $90 \%$ da culpa pelo fenômeno climático é da atividade humana, encontra-se um equívoco na leitura ou interpretação do Relatório do IPCC. Em suas páginas iniciais, onde tece considerações às conclusões do documento, encontra-se:

É muito provável que o aumento observado da concentração de gás metano é devido às atividades antropogênicas, predominantemente a agricultura e o uso de combustível fóssil, mas contribuições relativas a diferentes tipos de fontes não estão bem determinadas (IPCC, 2007, p. 4)

Em nota de rodapé, porém, é indicado o significado da expressão "muito provável" que é de $90 \%$. Portanto, essa porcentagem refere-se à chance de o aquecimento global ter causa humana e não como uma fração (quantidade) da culpa humana no fenômeno, o que é bem diferente. A matéria dá a impressão de que a causa humana das Mudanças Climáticas é algo inequívoco quando, na verdade, o relatório classifica de inequívoco somente o fenômeno climático e não a sua causa. Muitos jornais e revistas fizeram essa mesma afirmação do Diário Catarinense, cometendo, portanto, o mesmo erro.

A terceira inquietação apresentada pelo jornal diz respeito à inevitabilidade do fenômeno. A leitura jornalística desse trecho busca, evidentemente, o alarme. O catastrofismo e o pânico das imagens que acompanham a matéria é algo, realmente, evidente. O intuito de gerar a consciência do inevitável e do clima de catástrofe marcou os primeiros meses de cobertura do Aquecimento Global. O primeiro box da matéria traz três frases de presidentes do Brasil, dos EUA e da França, nas quais ressaltam a importância do relatório e confirmam o compromisso de seus países com as revelações trazidas pelo documento, bem como a preocupação com o futuro do planeta.

Em seguida, uma coluna que leva o título de "História vai condenar os poluidores", já aponta soluções para o problema planetário e, ao final, informa às providências que já haviam sido levantadas antes pelo Fórum Econômico Global, colocando o aquecimento global como um problema a cargo das grandes potências e não mais somente restritos a ecologistas. A 


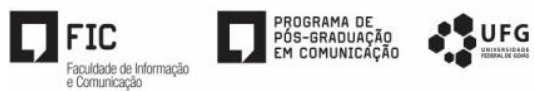

menção às espécies ameaçadas é feita, mas deixada em segundo plano diante da crise econômica que o fenômeno climático poderia surtir.

Na segunda página da matéria, há o destaque para as medidas e possibilidades, bem como para as oportunidades de negócio para o Brasil em vista do álcool. "Álcool será o combustível do futuro", diz o título do último box da reportagem, que traz o Aquecimento Global como grande oportunidade para a economia brasileira.

Função - A função informativa se apresenta, segundo Bueno (2007), como a que responde à necessidade de orientação do leitor. Nesse sentido, a notícia da publicação do Relatório IPCC e as informações ali constantes correspondem a essa necessidade e função do próprio jornal. O apelo da inevitabilidade e do catastrofismo, porém, dirige a atenção para a necessidade do controle da situação pelas grandes potências e favorece o clima de cobrança internacional por medidas que salvem o planeta.

A função política predomina na matéria, o que é evidenciado pelas frases dos presidentes, pelo tom alarmista da interpretação do IPCC e pela ausência de soluções individuais que pressuporiam uma função mais pedagógica ligada à participação dos cidadãos. Portanto, entre as funções do jornalismo ambiental recomendadas por Bueno (2007), reconhecemos a predominância da função política, já que a matéria chama a atenção para a necessidade da ação política como solução principal e clama pela cooperação internacional, ecoando o objetivo do próprio relatório.

Considerando que as funções do jornalismo ambiental podem e devem ser usadas em um aspecto também descritivo e crítico, acreditamos que se possa infundir a esse tipo de matéria aquilo que chamaríamos de função alarmista, uma clara característica da reportagem analisada e que se encontra presente também em uma grande quantidade de textos do objeto delimitado para análise. Tratamos essa abordagem alarmista como indicação do que afirma Weingart (2000), de que o alarmismo ou catastrofismo pode servir a uma série de interesses políticos.

Visão de meio ambiente - Parece-nos perceptível a influência de uma visão técnica em relação ao meio ambiente. Devido à preocupação com a crise dos recursos e com o impacto econômico das mudanças climáticas, assim como com as soluções políticas apontadas no sentido de fomentar determinadas condições econômicas em consonância com intervenções características das instituições internacionais, consideramos predominante a visão ecotecnocrática de meio ambiente. 


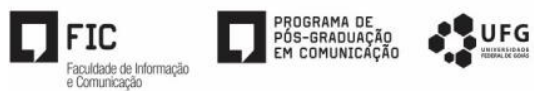

Segundo Caporal (2001), essa visão impõe-se na maioria do conteúdo de meio ambiente, quando esse se concentra nas consequências econômicas e trata o meio ambiente como um sistema gerenciável tecnicamente. Esse meio ambiente, como vimos, é visto como forma de obtenção de lucros ou prejuízos, distante, portanto, daquela visão naturalista pela qual é entendido como fim em si mesmo ou quando foca nos aspectos sociais.

Fontes - Quanto às fontes da matéria analisada, o IPCC é, evidentemente, uma fonte primária, ainda que consideremos o relatório do IPCC uma fonte documental, enquanto o órgão representa uma fonte institucional produtora desse documento. Conforme Hall, a fonte primária nem sempre coincide em ser também o definidor primário da notícia. Essa ressalva é importante para se compreender que o definidor é quem cria grande parte dos pressupostos. Nesse caso, consideramos que o definidor primário coincide com a fonte primária, embora não enquanto documento, mas enquanto órgão dono de credibilidade legada pelas Nações Unidas.

Essa autoridade se faz presente na figura da comunidade científica que usufrui da soberania do método científico como legitimador político (WEINGART, 2000). Temos, portanto, uma estrutura de autoridade que vai desde a ciência, enquanto símbolo justificador encarnado nas comunidades científicas, passando pelos órgãos representantes simultâneos da autoridade científica e política, até o documento expedido por essas entidades, que tem lugar de fonte primária.

\subsection{Segunda matéria em análise: "Mudanças sentidas na pele"}

No início de junho, o Diário Catarinense já começava a anunciar a publicação de um caderno especial sobre o Aquecimento Global. Ao todo, durante os primeiros seis meses de 2007, foram lançados dois cadernos, ambos em caráter essencialmente pedagógico, trazendo recomendações dos cientistas para que os próprios cidadãos pudessem contribuir com a redução do calor na Terra, por meio das mais variadas e simples atitudes cotidianas.

O primeiro caderno foi publicado no dia 5 de junho, em comemoração ao Dia do Meio Ambiente, com patrocínio da maior empresa de energia do estado. O caderno DC Documento trazia a grande reportagem de 11 páginas intitulada: "Terra sob ameaça. Como reduzir o aquecimento global".

A primeira matéria, "Para um 5 de junho promissor", começa enfatizando o calor sentido nos últimos 10 anos, ligando-o às previsões dos cientistas. $\mathrm{O}$ primeiro parágrafo da reportagem destaca:

Comun. \& Inf., Goiânia, GO, v. 20, n. 1, p. 115-130, jan./jun. 2017 
A população nunca sentiu tanto calor como nos últimos 10 anos. E as previsões não dão refresco. Cientistas garantem que o clima está sofrendo mudanças por causa do aquecimento global, uma consequência dos gases e vapores produzidos, principalmente, pela produção industrial e das queimadas.

A matéria chama a atenção para a relação entre o desmatamento das florestas brasileiras e as mudanças climáticas e termina por lembrar da iniciativa do Protocolo de Kyoto. Por fim, engloba as atitudes cotidianas do cidadão para ajudar a controlar o clima do planeta. A expressão “cientistas garantem”, comumente usada no jornalismo científico, traduz bem o tipo de expectativa alimentada nas conclusões de pesquisas das ciências naturais, bem como ampliações dessas conclusões a aspectos que dizem respeito ao comportamento individual ou coletivo.

Como nos lembra Morin (1999), nenhuma ciência pode garantir a validade universal de suas conclusões já que suas premissas dificilmente fazem parte do objeto daquela ciência e as consequências das conclusões também a extrapolam. Além disso, as descobertas e conclusões são sempre temporárias bastando uma única evidência em contrário para derrubar quaisquer vínculos de necessidade lógica ou causal. A garantia referida pela matéria diz respeito à validade social, ao consenso público necessário à ação política e econômica.

Uma outra matéria do mesmo caderno insiste na percepção do fenômeno global por meio da evidência dos dias quentes. O título, "Catarinenses sentem efeitos das mudanças", resume o lead, que assegura: "Os catarinenses sentem na pele os efeitos das mudanças climáticas. A redução da amplitude térmica no Estado, ou seja, a diminuição da variação entre a temperatura máxima e mínima, está aí para quem quiser ver - e sentir”.

O técnico entrevistado, o meteorologista e geógrafo da Empresa de Pesquisa Agropecuária e Extensão Rural de Santa Catarina (Epagri), não faz previsões, mas descreve algumas conclusões, em nível local, sobre o tipo de calor sentido no último verão, chamando a atenção para o provável prejuízo para a agricultura, além de enfatizar precedentes históricos.

Essa matéria individual, portanto, não cita o IPCC nem os cientistas que previram o Aquecimento Global, embora utilize seus pressupostos como certos. Parece ser o repórter, e não um cientista, que vai comprovando o fenômeno por meio de evidências regionais. Em dado momento da matéria, escreve o repórter:

Se, apesar dos estudos apresentados pelo geógrafo da Epagri, ainda restar alguma dúvida sobre o aquecimento global, basta verificar a variação térmica ao longo do século, que, revelam estudos da Nasa, pulou dos $13,6^{\circ} \mathrm{C}$, registrados no ano de 1880 , para $14,4^{\circ} \mathrm{C}$, em 2005 . Ou, sem precisar olhar 
tão longe, lembrar do ano passado, quando 195 municípios catarinenses decretaram estado de emergência provocado pela estiagem.

O texto parece dialogar com um cético que, aparentemente, crê que as mudanças na temperatura são naturais ou não estão ocorrendo. Porém, a dúvida dos chamados céticos, que já naquela época questionavam as conclusões do IPCC no resto do mundo, estava na causalidade entre a emissão de gases e a temperatura, um vínculo de necessidade que até $A l$ Gore, no filme premiado "Uma verdade inconveniente", disse não ter muita certeza. Embora a matéria não tenha citado nenhuma argumentação cética no texto, ela parece dialogar com a suposta divergência a respeito da mudança ou não do clima da Terra, o que absolutamente não representava o ponto do debate científico que ocorria fora da mídia, nos círculos científicos internacionais.

Assim, o salto de temperatura anual que a matéria sugere como prova do aquecimento global, igualmente não traz nenhuma novidade substancial. Esses dados foram contestados, na época, por cientistas da Metsul, empresa meteorológica do Rio Grande do Sul com pouca ou nenhuma repercussão na mídia nacional. Essa mesma empresa dizia que o perigo global, segundo os cientistas gaúchos, não era resultante da ação humana, mas natural, e que a preocupação devia se dirigir à suspeita considerada mais realista de um resfriamento natural, algo que traria bem mais prejuízos e mortes.

Conforme as previsões desses últimos cientistas, aqueles 195 municípios que sofreram com a estiagem em 2006, conforme citado na matéria, questionamos: eles teriam tido mais sorte do que as cerca de 150 cidades catarinenses que sofreram com a neve no inverno de $2013 ?$

Em seguida, a matéria cita o meteorologista que afirma não existir, até hoje, estudos para mostrar os reflexos do fenômeno global em Santa Catarina, "mas observações já apontam para o que os cientistas comentam sobre as mudanças do clima", afirma o geógrafo. Isso significa que, não havendo nenhum estudo regional para comprovar o que dizem os cientistas internacionais, a confirmação da hipótese do aquecimento global restringe-se às observações que coincidem com "o que os cientistas comentam".

Assim, podemos dizer que se torna objeto de observação dos cientistas individuais só o que coincide com a confirmação de hipóteses aceitas pela comunidade científica, já que é considerado objeto da ciência somente aquilo que pode ser por ela mensurável. Se os cientistas do mundo inteiro fazem declarações seguindo as opiniões aceitas pela categoria, o 
que dizer de um jornalismo que trata hipóteses científicas como opiniões e as validam socialmente como consensos universais?

A matéria expõe um gráfico que é exatamente o mesmo publicado junto à reportagem de anúncio do lançamento do relatório do IPCC, em 3 de fevereiro. Apesar de haver modificação no tom das previsões, a hipótese lançada pelo IPCC parece seguir inalterada, segundo suas suposições de causalidade.

Função - A análise do caderno especial publicado pelo DC indica a predominância da função pedagógica do jornalismo ambiental praticado ali, embora seja patente a presença de matérias que anunciam a necessidade de um pacto global para conter as mudanças e também de páginas e gráficos de cunho informativo.

Um anúncio do filme "Uma verdade inconveniente" estampa uma das páginas intitulada: "vale a pena assistir". Ao lado, a matéria "consciência em sala de aula" traz a história de uma aluna que luta para conscientizar a sociedade por meio de sugestões de modo de vida aos colegas e aos pais. Destaca o papel dessa consciência para a educação das crianças e para a modificação dos comportamentos por um mundo melhor.

Uma outra matéria do caderno faz uma agradável propaganda do Carbon Free, cuja maior vantagem é a diminuição da emissão de gás carbônico na atmosfera, causadora do Aquecimento Global. Junto a essa matéria, propostas de "um novo estilo de vida", que surgem a partir da diminuição do consumo e que contam com entrevistas de membros de Organizações Não Governamentais (ONGs), recomendam novos comportamentos à população em vista dos desafios climáticos.

Visão e formação discursiva - Na análise da formação discursiva e da visão de meio ambiente exposta na grande reportagem do DC Documento, encontramos características de uma visão ecotecnocrática relativa aos prejuízos da agricultura e às consequências econômicas, bem como a tendência a aplicar aos comportamentos humanos uma visão técnica extraída das ciências naturais. Porém, o discurso predominante parece ter sido o ecossocial.

Como explicamos no primeiro capítulo deste trabalho, a formação discursiva, especificada por Escobar (1995), é formada por um arranjo entre as perspectivas culturalista e ecossocialista, ambas tidas como descendentes de modelos marxistas e gramscistas, que representam influências teóricas de uma práxis comum a partir dos Estudos Culturais.

Essa visão propõe modelos de interações políticas baseados na existência de papéis sociais construtores da dinâmica histórica, que, por sua vez, é fundamentada pela relação com os bens econômicos e materiais. A função da educação, nesse sentido, é essencial, já que a 
conscientização (herdeira da consciência de classe contra a alienação promovida pelo capital) é o principal fator de mudança social.

Fontes - O relatório do IPCC só apareceu nesse caderno quando necessário a uma função informativa, o que, no caso, ocupou lugar acessório e não principal. Não obstante, o documento da ONU e as afirmações tratadas nos meses anteriores, já consideradas amplamente conhecidas, fazem do IPCC um definidor primário, embora só apareça como fonte secundariamente.

O definidor primário, portanto, é institucional. Cientistas locais, como o técnico da Epagri, membros de ONGs e pesquisadores da Universidade, fizeram parte do rol de fontes utilizadas. Essas são as fontes especializadas, em grande maioria. É possível afirmar que o DC Documento analisado corresponde ao que seria um trabalho completo de jornalismo ambiental, no qual a multiplicidade das fontes aparece em sua plenitude. Sendo a função do jornalismo ambiental, tal como afirma Bueno, chamar a atenção para os perigos existentes, esse conjunto de matérias obedece, em grande parte, a esse intento.

$* * *$

Como síntese dessa etapa do presente trabalho, é possível estabelecer algumas considerações:

- A relação entre as funções do jornalismo ambiental e as formações discursivas verificadas nas matérias: a função informativa, no jornalismo ambiental, ao utilizar o discurso naturalista, gera pressões por meio da característica alarmista, o que implica conclusões de ações administrativas e econômicas.

- O percurso dos critérios de noticiabilidade: os valores-notícia estabelecem um conjunto de motivações geradas e geradoras das condições para cada etapa. O risco de extinção de espécies, típico valor-notícia do jornalismo ambiental mais naturalista, somado às mudanças geológicas e marítimas, dão às matérias o tom alarmista e catastrófico que, aos poucos, dirige-se para a preocupação com os prejuízos materiais e financeiros. O perigo das mudanças na economia global e das perdas nacionais, gerador do clima de crise, tornam possíveis as sugestões de mudanças no âmbito social e cultural dos cidadãos.

- O poder da ciência e a credibilidade de dados científicos como critério para a escolha de fontes: diz respeito ao privilégio de determinadas fontes e a presença do poder científico como legitimador político. Acompanhando o processo dos critérios de valoração das pautas ambientais, a escolha de fontes se completa também a partir do seu grau de credibilidade. Diante dos resultados que apontam uma predominância da fonte institucional nas matérias, é 


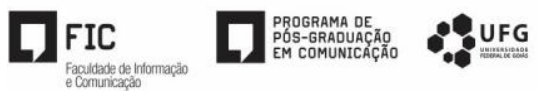

possível sugerir a matiz de sua intencionalidade e considerar sua filiação a órgãos supranacionais como as Nações Unidas. A fonte do IPCC, como a mais consultada, representou o poder simbólico da ciência e sua influência vista como preferencial na sociedade.

\section{CONSIDERAÇÕES FINAIS}

\subsection{Os porquês - a fé na Ciência}

O sociólogo português Boaventura de Sousa Santos lançou, em 1987, "Um discurso sobre as ciências", uma versão atualizada e mais aprofundada de sua conferência "Oração de Sapiência", proferida na abertura solene das aulas da Universidade de Coimbra, em 1985, onde atua até hoje. Como diz o próprio autor, o texto teve uma carreira feliz, mas enfrentou também alguns percalços. Nos anos noventa, foi alvo de uma "nova guerra das ciências" travada entre positivistas e antipositivistas, entre realistas e construtivistas. O objetivo era denunciar as supostas debilidades das posições antipositivistas ditas "pós-modernas".

Em "Um discurso sobre as ciências", Santos apresenta uma posição epistemológica antipositivista, sim. Questiona a teoria representacional da verdade e a primazia das explicações causais e defende que "todo conhecimento científico é socialmente construído, seu rigor tem limites inultrapassáveis e que sua objetividade não implica em sua neutralidade" (2010, p. 9). A exemplo de Fritjof Capra e Edgar Morin, o lusitano também critica um paradigma dominante e explicita a emergência de um novo paradigma. Em suma, Santos nunca quis destruir as ciências, mas vislumbrá-la por outra epistemologia. É o que tem feito em seus livros, ensaios e artigos publicados em Portugal, no Brasil e em vários países. Esse autor nos ajuda a entender "os porquês" para essa situação aqui apresentada.

Santos (2010) salienta que o fabuloso progresso tecnológico das últimas três ou quatro décadas podem nos iludir a pensar que os personagens da revolução científica, inaugurada no século XVI, seriam pré-históricos. A rigor, qualquer inovação ocorrida nesses quatrocentos anos é evolução, fruto ou consequência de ideias brotadas a partir de Copérnico, Galileu e Newton. A racionalidade, o experimentalismo e o rigor da lógica metodológica fizeram o homem moderno substituir sua fé no divino pela fé em sua inteligência e em suas próprias mãos.

Como um paradigma dominante, o pensamento científico moderno induz a uma racionalidade que configura um modelo totalitário, como ressalta o autor 
[...] na medida em que nega o caráter racional a todas as formas de conhecimento que não se pautarem pelos seus princípios epistemológicos e por suas regras. É essa a sua característica fundamental e a que melhor simboliza a ruptura do novo paradigma com os que o precederam (SANTOS, 2010, p. 21).

Daí inferir um questionamento: o homem, como personagem central do mundo, teria trocado Deus pela Ciência?

Em seu ensaio "Para além do pensamento abissal" (2007), descreve a bipolarização do mundo por meio de um sistema de distinções visíveis e invisíveis. São linhas, limites imaginários, que separam a realidade social em dois mundos - norte-sul, civilizado-selvagem, colonizador-colonizado. No campo do conhecimento, esse pensamento consiste na concessão, à ciência moderna, do monopólio da distinção universal entre o verdadeiro e o falso. O caráter exclusivo desse monopólio está no cerne da disputa epistemológica moderna entre as formas científicas e as não científicas de verdade. A ciência, como conhecimento monopolista, privilegia uma epistemologia das consequências, que vêm sempre antes das causas.

A fé cega nas ciências e no monopólio das verdades científicas têm sido motivo e justificativa para a Imprensa atribuir total e irrestrita credibilidade às fontes tidas como fidedignas. Não só os centros de pesquisa, como qualquer organização - pública ou privada -, têm procurado se equipar com os instrumentos criados pelas ciências. Seu braço operativo, a tecnologia é símbolo do moderno, do atual, da eficiência. Para o Diário Catarinense, não importa as causas do aquecimento global, mas interessa o que o relatório elaborado por cientistas renomados de 150 países tem a dizer sobre o tema.

Por que? Santos (2010) nos lembra que a ciência moderna se constitui a partir da revolução científica do século XVI e foi desenvolvida nos séculos seguintes no domínio das ciências naturais. No século XIX, esse modelo de racionalidade se estende às ciências sociais emergentes. Augusto Comte acreditava ser possível usufruir de toda a experiência das ciências naturais para a nova ciência. Tal equívoco hoje já é consensual.

Importa também recordar, como já escrevemos anteriormente (IJUIM, 2014, p. 2), que os modelos jornalísticos que utilizamos até hoje foram estabelecidos no século XIX, quando o fazer jornalístico passou de atividade artesanal para empresa de comunicação de massa, um veículo da indústria cultural, e adotou os mesmos métodos e procedimentos de uma fábrica do sistema capitalista. Essa configuração aconteceu no clima e na circunstância da predominância do pensamento científico moderno. Esses princípios operaram tanto nas práticas científicas como nas práticas comunicacionais. 
O pensamento científico e o pensamento jornalístico, portanto, confluíram na configuração do modelo de se produzir notícias. O que é objetivo, real, mensurado, útil, exato, preciso se sobrepõe ao subjetivo, relativo, inútil, vago. O pensar e o fazer jornalísticos, por essa lógica, privilegiam o que culturalmente é considerado capaz e competente para fornecer informações confiáveis - a ciência e seus agentes.

Por outro lado, essa racionalidade reflete nas decisões do que é notícia e nas formas de visualizar a pauta. Em outros termos, nos critérios de noticiabilidade, o que é real, objetivo e exato? Os chamados valores-notícia, que estão em qualquer manual de redação, instituem critérios como novidade, impacto, notoriedade, importância, caráter inesperado, entre outros.

Ao que parece, o Diário Catarinense e tantos outros órgãos de imprensa, pelo menos no caso do Aquecimento Global, preferem privilegiar o que há de impactante por meio da notoriedade de suas fontes oficiais - fidedignas. Se a ciência dá mais importância às consequências que às causas, a Imprensa também tem se reservado à comodidade de publicar as consequências e deixado, em segundo plano, uma de suas principais missões - investigar outras possibilidades, outras verdades.

Na divulgação do Quinto Relatório do IPCC, em 2014, a imprensa brasileira e em particular o Diário Catarinense, não agiu de maneira diferente. Com menor ênfase que em 2007, os órgãos de imprensa mantiveram o tom alarmista e recorreram à notoriedade do comitê da ONU, como se pode observar nos títulos a seguir, em que o relatório e a ONU são mantidos como fontes primárias e/ou definidores primários.

Mudança do clima afeta a todos e está acontecendo agora, alerta IPCC

Valor Econômico - 31/03/2014

Impacto do aquecimento global será 'grave e irreversível', diz ONU

BBC Brasil - 31/03/2014

Aquecimento da Terra pode ser o responsável por onda de calor

Diário Catarinense - Planeta febre - 09/02/2014

2014 pode ser o ano mais quente da história do planeta

Diário Catarinense - Efeito do El Niño - 29/10/2014

Por essas razões, devemos supor que os modelos jornalísticos em prática - pela Imprensa e em particular pelo Diário Catarinense - respondem às duas questões aqui apresentadas 1) a agenda da ONU e 2) o discurso ditado pelos relatórios do IPCC. A adesão irrestrita do periódico é notada pelo agendamento de um órgão supostamente inquestionável, as Nações Unidas, e pelo documento chancelado pela ciência. Prevalece a fé na ciência. 


\section{REFERÊNCIAS}

ANDI - Agência de notícias dos direitos da infância. Mudanças climáticas na imprensa brasileira: uma análise comparativa de 50 jornais nos períodos de julho de 2005 a junho de 2007; julho de 2007 a dezembro de 2008. Disponível em:

<http://www.mudancasclimaticas.andi.org.br/node/608>. Acesso em: 20 out. 2013.

BUENO, Wilson da Costa. Comunicação e jornalismo ambiental: teoria e pesquisa. São Paulo: Majoara Editorial, 2007.

Jornalismo ambiental: além do conceito. Revista Desenvolvimento e Meio Ambiente. Curitiba: UFPR, n. 15, p. 33-44, 2007.

CAPORAL, Francisco Roberto; COSTABEBER, José Antônio. Agroecologia e sustentabilidade: base conceptual para uma nova extensão rural. In: Encontro Internacional sobre Agroecologia e Desenvolvimento Rural Sustentável, 2001, Rio Grande do Sul. Anais eletrônicos... Botucatu: Instituto Giramundo Mutuando, 2001. Disponível em:

<http://coral.ufsm.br/desenvolvimentorural/textos/13.pdf>. Acesso em: 01 nov. 2013.

ESCOBAR, A. EI desarrollo sostenible: diálogo de discursos. Ecología Política, Barcelona: Icaria, 1995.

HERCOVITZ, Heloiza Golspan. Análise de conteúdo em jornalismo. In: Metodologia de pesquisa em jornalismo. Petrópolis: Vozes, 2008. p. 123-142.

IJUIM, Jorge Kanehide. Ciência e Jornalismo: Apontamentos Sobre as Ideias de Boaventura de Sousa Santos para a Compreensão do Jornalismo. Revista Ação Midiática: Estudos de Comunicação, Sociedade e Cultura, Paraná, n. 7, p. 1-15, 2014. Disponível em: <http://revistas.ufpr.br/acaomidiatica/article/view/36297>. Acesso: 27 jul 2017.

IPCC - Painel Intergovernamental sobre Mudança do Clima. Mudança do clima 2007: Mitigação da mudança do clima. Contribuição do grupo de trabalho III ao quarto relatório de avaliação do Painel Intergovernamental sobre Mudança do Clima. Sumário para os formuladores de políticas. Bancoc: Painel Governamental, 2007.

MCCOMBS, Maxwell. A teoria da agenda: a mídia e a opinião pública. Petrópolis: Vozes, 2009.

MEDINA, Cremilda. Ciência e jornalismo: da herança positivista ao diálogo dos afetos. São Paulo: Summus, 2008 
MORIN, Edgar. Ciência com consciência. 3. ed. Tradução Maria D. Alexandre e Maria Alice Sampaio Dória. Rio de Janeiro: Bertrand do Brasil, 1999.

PAINTER, James. Summoned by science: reporting climate change at Copenhagen and beyond. Challenges. London: Oxford's Reuters Institute for the study of journalism, 2010.

SANTOS, Boaventura de Sousa. Um discurso sobre as ciências. 7. ed. São Paulo: Cortez, 2010.

Para além do pensamento abissal: das linhas globais a uma ecologia de saberes. Revista Crítica de Ciências Sociais, Coimbra, n. 78, p. 3-46, out. 2007. Disponível em: $<$ http://www.ces.uc.pt/myces/UserFiles/livros/147_Para\%20alem\%20do\%20pensamento\%20 abissal_RCCS78.pdf $>$. Acesso em: 07 jun. 2014.

TRAQUINA, Nelson. O Poder do Jornalismo: Análise e Textos da Teoria do Agendamento. Coimbra: Minerva, 2000.

WEINGART, Peter; ENGELS, Anita; PANSEGRAU, Petra. Risks of communication: discourses on climate change in science, politics, and the mass media. [s.l.]: Public Understanding of Science, 2000. 